\title{
DDS: A Decade of Distinguished Scholarship
}

\author{
Jonathan D. Kaunitz ${ }^{1,2}$ (]) Meghan Keeffe ${ }^{3}$
}

Published online: 5 June 2020

(c) This is a U.S. Government work and not under copyright protection in the US; foreign copyright protection may apply 2020

As we have now been involved as Editor-in-Chief and Managing Editor of Digestive Diseases and Sciences for almost a decade, we would like to reflect on the many changes that have occurred in order to thank the many associate editors, authors, and reviewers for helping shape DDS into its current form. Emmet Keeffe and his daughter, Meghan, who joined DDS as Editor-in-Chief and Managing Editor in 2008, enthusiastically revitalized the journal. Although the opportunity for Jonathan to become editor was rooted in Emmet's tragic and untimely death in 2011, Emmet's leadership provided the impetus to innovate and expand according to his philosophy of quality, integrity, and creativity, which through improvements and steady work, has enhanced the stature, reach, and influence of DDS. We are both certain Emmet would be thrilled by DDS's progress in recent years.

\section{New Features}

One of the most satisfying aspects of being editor is the freedom to add new features, which provide outlets for scholars with expertise in specific areas and also open up fresh readers with matching interests. Based on our original affiliation with the Gastrointestinal Research Group, several features are aimed at involving students, trainees, fellows, and young faculty, sometimes with their first published work. Others provide perspective on the origins of medical advances, that can often be traced to a few publications that fundamentally changed the field. We also now have four case conference series covering a variety of disciplines and several leading institutions. Of particular note are the Special Issues that

Jonathan D. Kaunitz

jake@ucla.edu

1 Medical Service, West Los Angeles VAMC, Los Angeles, CA, USA

2 Departments of Medicine and Surgery, David Geffen School of Medicine at UCLA, Los Angeles, CA, USA

3 Mill Valley, CA, USA cover an area of interest in depth and breadth, serving as a definitive resource. The special features are listed in Table 1, in chronological order of appearance.

\section{Editors}

One of the most gratifying aspects of DDS is the superb quality of its editors, which serve as the interface between the journal and our contributors. All are faculty based at prestigious institutions who have not only a command of the field but also have a sharp eye for managing submissions, ensuring a consistently high level of quality for our published work. Current and past editors are listed in Table 2.

\section{Articles}

DDS continues to print high-impact articles in all fields of GI, whether luminal, liver, basic, translational, or clinical. Table 3 lists the 10 most highly cited articled published in DDS in the years 2010-2019. Gratifyingly, the list contains examples of every type and category of article that DDS publishes, including reviews and original articles. Although the total number of published articles has remained relatively constant, the number of original articles has decreased due to the increasing number of published editorials, reviews, and special sections (Fig. 1). Also notable is that the number of submissions has increased almost every year since 2008, with each recent year now setting a record high for the number of submitted articles received (Fig. 2).

\section{Reviewers}

A journal is only as good as its reviewers, since these anonymous volunteers are essential to perpetuate the process of peer review, the key principle that underlies the scientific method. With the number of submissions increasing yearly as shown in Fig. 2, each editor has handled an increasingly 
Table 1 Special features listed in descending order of length of publication in DDS

\begin{tabular}{ll}
\hline Feature name & Editor(s) \\
\hline Stanford Multidisciplinary Seminars & George Triadafilopoulos \\
UNM Clinical Case Conferences & Dennis McCarthy \\
Special Issues & Robert S. Bresalier \\
Mentored Reviews & Frank Friedenberg \\
Paradigm Shifts in Perspective & Jonathan Kaunitz \\
Profiles and Perspectives & Lawrence S. Friedman \\
Fellows and Young GIs & Deborah D. Proctor, Jill Deutsch, Jared Macklin, Uyen Kim To \\
DDS Citation Classics & Jonathan Kaunitz \\
Multidisciplinary Seminars: IBD & Matthew Hamilton, Gary Lichtenstein, Uma Mahadevan, \\
& Fernando Velayos \\
DDS-SIRC Cooperative Conferences & Augusto Lauro \\
\hline
\end{tabular}

large load of submissions. DDS is fortunate to have a dedicated cohort of reviewers who have helped editors evaluate the submissions that have been sent out for review; as an example, in 2019, 1241 reviewers completed 2292 manuscript reviews. We deeply thank our reviewers for continuously increasing the quality and impact of the accepted submissions.

\section{Editorial Board}

Another key element necessary for a journal's success is it Editorial Board. Ours is composed of 129 globally-based leading academics who have meaningfully contributed to DDS, either by contributing editorials, helping with peer review, recommending associate editors, attending Editorial Board meetings, and contributing original articles and features. These many distinguished, expert, and influential Editorial Board members have also been instrumental in the growth of the journal's stature and influence in the past decade.

\section{Impact}

The Journal Impact Factor (JIF) has become the de facto "coin of the realm" when it comes to ranking the relative worth of journals. Many scientists are unaware that the
JIF was initially developed as a tool for librarians seeking to order the journals of the most value to their clients. A simple formula, consisting of dividing the number of citations calculated at a time in year $\mathrm{X}$ to articles published in years X-1 and X-2, and dividing that number by the number of "citable items" published in years X-1 and X-2 yields an average number of times that each "citable item" was cited following its publication. "Citable items" are defined as publications of a certain length and number of literature citations in their bibliography. The problem with this formula, as has been extensively discussed [1-4], is that truly groundbreaking discoveries sometimes take several years to be accepted by the scientific community and hence be cited by others, and thus would be mostly missed by the JIF. Furthermore, reviews, guidelines, statistical summaries, and methods papers are highly cited not due to their paradigmshifting discoveries, but due to their overall value and utility to other authors. Further complicating matters is that the JIF is a simple mean that does not account for outliers. The frequency curve of citations/item is non-ideally distributed, generally with a long tail, and thus is subject to distortions of the simple arithmetic mean by a small number of highly cited publications.

Another issue that affects the JIF has to do with affiliation with a scientific society. DDS is not owned by or formally affiliated with any scientific society. The advantages of society affiliations are numerous, including the publication of highly cited guidelines and major clinical trials, being able 
Table 2 Current and emeritus editors of DDS since 2010

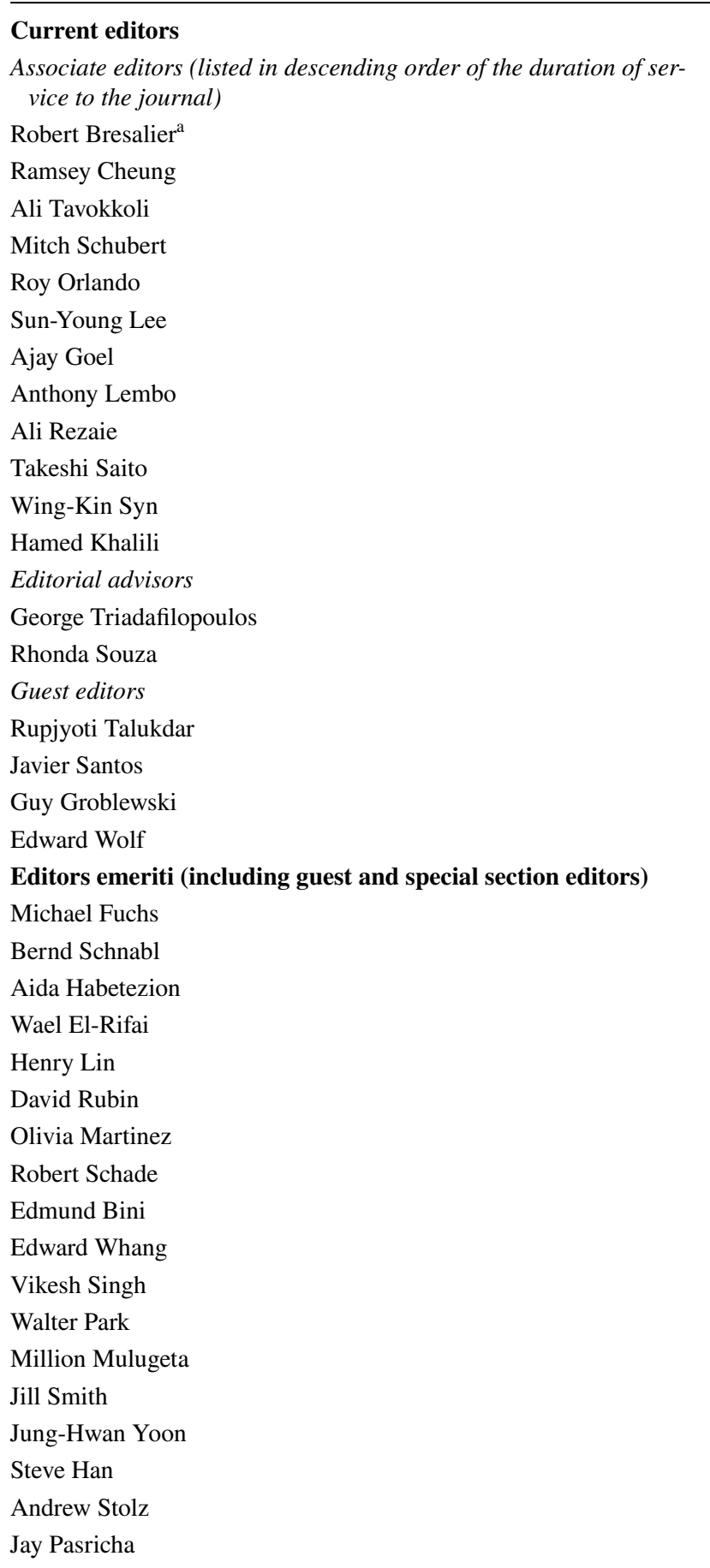

${ }^{\text {a }}$ Special Issues Editor to vet its editors through an extensive committee network, having large and active publicity staff, and being featured in the society's meetings, giving it the imprimatur of quality valued by authors. Absent these advantages, DDS must fight for recognition among the many other journals in the field. To us, this is a worthy challenge that can be transcended with attention to excellence, innovation, fairness, integrity, and respect for the needs and exigencies of our editors, reviewers, and authors. Furthermore, this lack of affiliation or ownership gives DDS a nimbleness to quickly adapt and expand, a feature that we particularly value.

Figure 3 lists key bibliometric statistics for DDS from 2008 to 2018 in order to give an indication of how far the journal has progressed since Emmet and Meghan took over in 2008. These data are compiled annually by Scimago and Clarivate Analytics, using either simple formulæ or advanced algorithms designed to gauge how a journal measures up against its peers. The leading indicator, the JIF, has increased $86 \%$ from 2008 to 2018 , an encouraging gain. Its closest cousin is the Scimago "Cites per document-2 years", which has a formula similar to the JIF, although the number diverges somewhat, likely due to variations of factors used to calculate the score. The Scimago Journal Rank or SJR uses an iterative process that not only takes into account the number of citations per article but also the prestige of the journals that cite the article. The SJR has placed DDS in the first quartile of GI-Liver journals for the years 2016-2018. Other bibliometrics include the Clarivate InCites Journal Citation Report Influence Factor that has also nearly doubled since 2008 . These bibliometric measures are described in detail in several publications $[5,6]$. We will leave it up to the reader to assess the relative standing of DDS among its peers in the biomedical literature, noting that as flawed as the JIF is, no consensus has been reached about a suitable replacement. As a Springer Nature journal, we will adhere to the sound advice of our publisher [1-3] by not emphasizing or further publicizing our JIF to our readers.

\section{Concluding Comments}

We would like to take this opportunity to thank our editors, authors, reviewers, and readers, who have helped bring DDS to its current status of an increasing presence in the GI journal 
Table 3 The top 10 most cited articles published in Digestive Diseases and Sciences in the years 2010-2019

1. Kappelman MD, Moore KR, Allen JK, Cook SF: Recent Trends in the Prevalence of Crohn's Disease and Ulcerative Colitis in a Commercially Insured US Population. Digestive Diseases and Sciences 2013, 58(2):519-525.[238]

2. Lewis JR, Mohanty SR: Nonalcoholic Fatty Liver Disease: A Review and Update. Digestive Diseases and Sciences 2010, 55(3):560-578. [213]

3. Arteh J, Narra S, Nair S: Prevalence of Vitamin D Deficiency in Chronic Liver Disease. Digestive Diseases and Sciences 2010, 55(9):2624-2628. [206]

4. Malaguarnera M, Vacante M, Antic T, Giordano M, Chisari G, Acquaviva R, Mastrojeni S, Malaguarnera G, Mistretta A, Volti GL et al: Bifidobacterium longum with Fructo-Oligosaccharides in Patients with Non Alcoholic Steatohepatitis. Digestive Diseases and Sciences 2012, 57(2):545-553. [194]

5. Song JN, Bai ZG, Han W, Zhang J, Meng H, Bi JT, Ma XM, Han SW, Zhang ZT: Identification of Suitable Reference Genes for qPCR Analysis of Serum microRNA in Gastric Cancer Patients. Digestive Diseases and Sciences 2012, 57(4):897-904. [182]

6. Sheen E, Triadafilopoulos G: Adverse Effects of Long-Term Proton Pump Inhibitor Therapy. Digestive Diseases and Sciences 2011, 56(4):931-950. [161]

7. Codling C, O’Mahony L, Shanahan F, Quigley EMM, Marchesi JR: A Molecular Analysis of Fecal and Mucosal Bacterial Communities in Irritable Bowel Syndrome. Digestive Diseases and Sciences 2010, 55(2):392-397. [154]

8. Wang HB, Wang PY, Wang X, Wan YL, Liu YC: Butyrate Enhances Intestinal Epithelial Barrier Function via Up-Regulation of Tight Junction Protein Claudin-1 Transcription. Digestive Diseases and Sciences 2012, 57(12):3126-3135. [149]

9. Peterson KA, Thomas KL, Hilden K, Emerson LL, Wills JC, Fang JC: Comparison of Esomeprazole to Aerosolized, Swallowed Fluticasone for Eosinophilic Esophagitis. Digestive Diseases and Sciences 2010, 55(5):1313-1319. [145]

10. Softic S, Cohen DE, Kahn CR: Role of Dietary Fructose and Hepatic De Novo Lipogenesis in Fatty Liver Disease. Digestive Diseases and Sciences 2016, 61(5):1282-1293. [135]

Numbers in [brackets] denote the total number of citations as of April 9, 2020. Data provided by Clarivate Analytics

Fig. 1 Number of items published by DDS 2010-2019. Note the marked decline in the number and percentage of original publications over this timespan

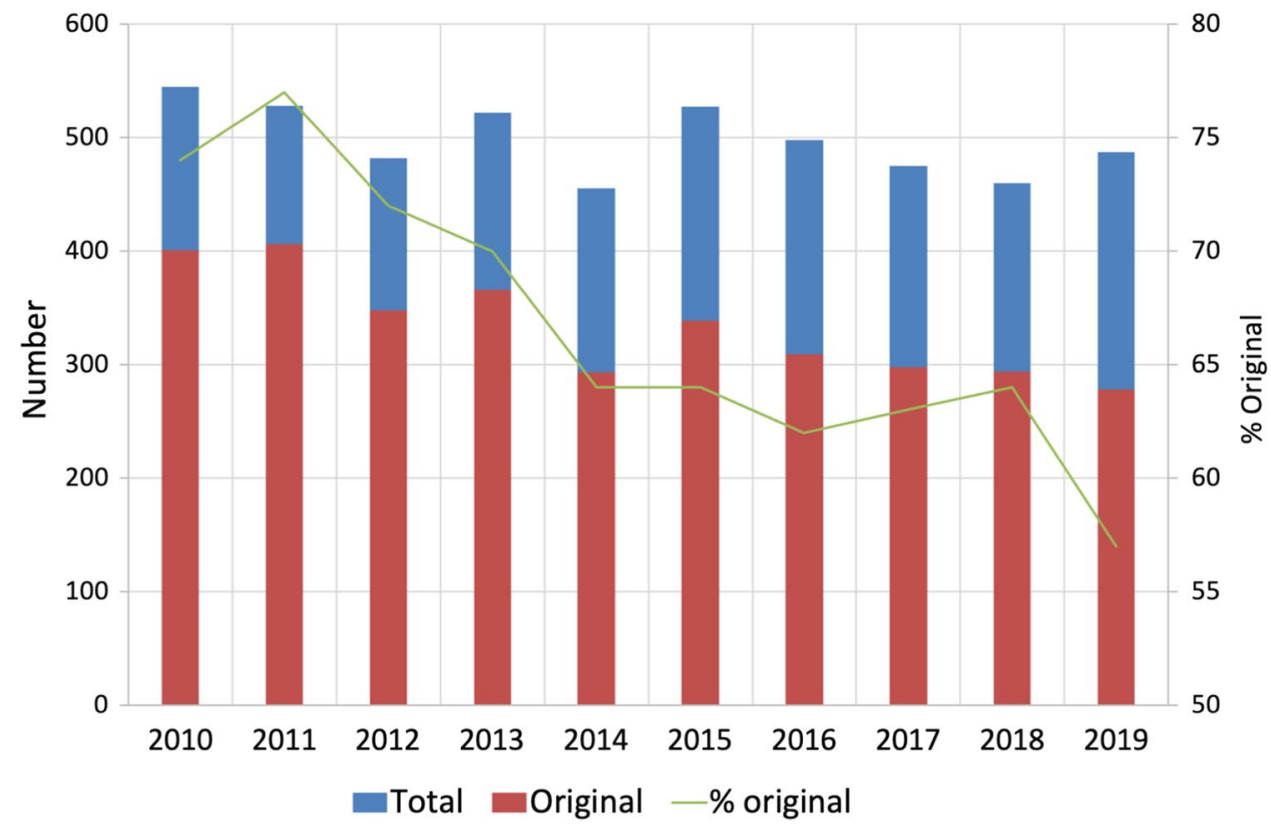

universe. We would especially like to thank our publisher's representative, Melissa Ramondetta of Springer Nature, for providing the wide latitude and support for creating new features while upholding the journal's integrity through upholding all of our efforts to improve the journal's scientific content, scope, and rigor. We look forward to continuing serve the scientific and clinical community with articles that provide insight into scientific observations and improve the care of our patients. 
Fig. 2 The number of submissions received by DDS/year since 2008
2600

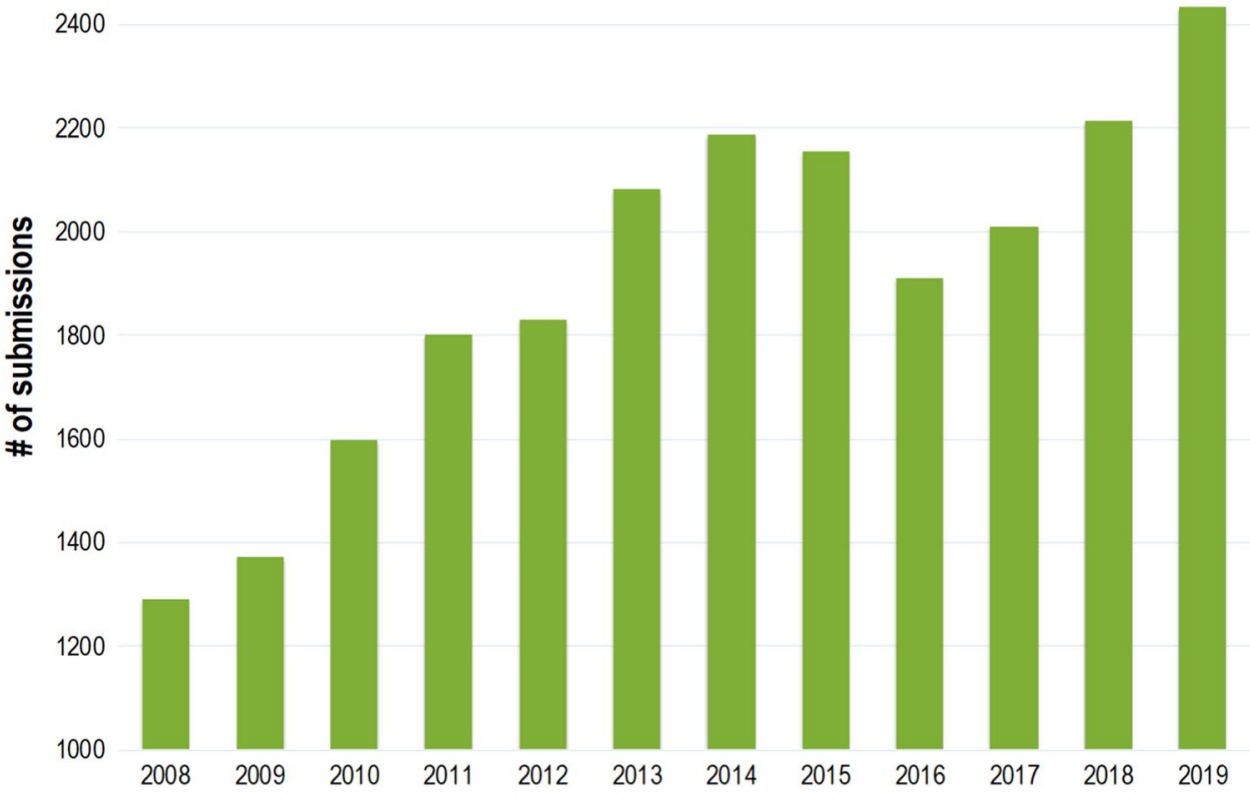

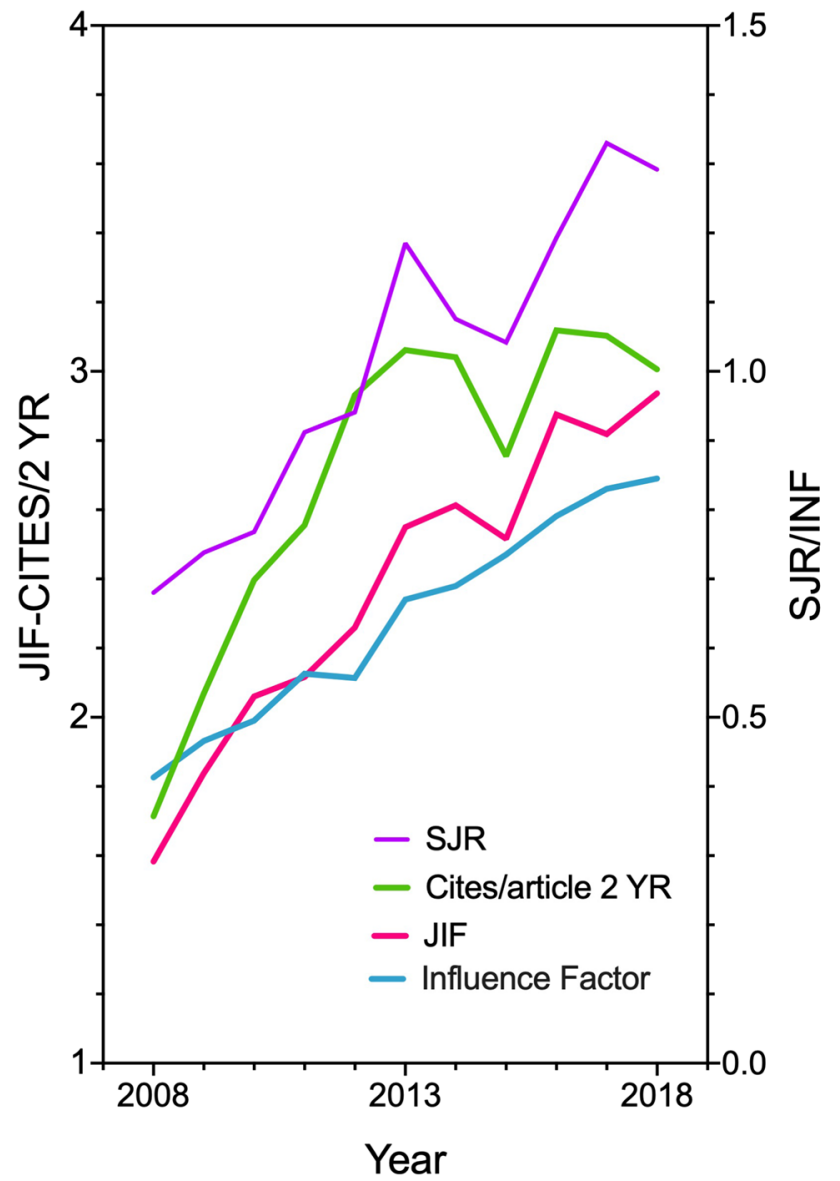

Fig. 3 Selected bibliometric data for Digestive Diseases and Sciences 2008-2018. JIF: Clarivate Journal Impact Factor; SJR: Scimago Journal Ranking; Cites/2 year: Scimago Citations per Document (2 years); INF: Clarivate Influence Factor. For details see text

\section{References}

1. Wouters $P$, Sugimoto $C R$, Larivière $V$, et al. Rethinking impact factors: better ways to judge a journal. Nature. 2019;569:621-623.

2. Anonymous. On impact. Nature. 2016;535:466.

3. Callaway E. Beat it, impact factor! Publishing elite turns against controversial metric. In: Nature. Vol. 535, ed. England; 2016:210-211.

4. Kaldas M, Michael S, Hanna J, Yousef GM. Journal impact factor: a bumpy ride in an open space. J Investig Med. 2020;68:83-87.

5. Roldan-Valadez E, Salazar-Ruiz SY, Ibarra-Contreras R, Rios C. Current concepts on bibliometrics: a brief review about impact factor, Eigenfactor score, CiteScore, Scimago Journal Rank, Source-Normalised Impact per Paper, H-index, and alternative metrics. Ir J Med Sci. 2019;188:939-951.

6. Roldan-Valadez E, Rios C. Alternative bibliometrics from impact factor improved the esteem of a journal in a 2-year-ahead annual-citation calculation: multivariate analysis of gastroenterology and hepatology journals. Eur J Gastroenterol Hepatol. 2015;27:115-122.

Publisher's Note Springer Nature remains neutral with regard to jurisdictional claims in published maps and institutional affiliations. 